\title{
Techno-Economic Analysis of Several Energy Storage Options for Off-Grid Renewable Energy Systems
}

\author{
Juan Lata-García ${ }^{1,2}$, Francisco Jurado ${ }^{2}$, Luis M. Fernández- \\ Ramírez $^{3}$, Pablo Parra ${ }^{1}$, Víctor Larco ${ }^{1}$ \\ ${ }^{1}$ Department of Electrical Engineering GIPI, Universidad Politécnica Salesiana \\ Guayaquil, Ecuador, jlatag@ups.edu.ec,pparra@ups.edu.ec, vlarco@ups.edu.ec \\ ${ }^{2}$ Research Group in Research and Electrical Technology (PAIDI-TEP-152), \\ Department of Electrical Engineering, EPS Linares, University of Jaén, 23700 \\ Linares, Jaén, Spain, fjurado@ujaen.es \\ ${ }^{3}$ Research Group in Electrical Technologies for Sustainable and Renewable \\ Energy (PAIDI-TEP-023), Department of Electrical Engineering, EPS Algeciras, \\ University of Cádiz, 11202 Algeciras, Cádiz, Spain, luis.fernandez@uca.es
}

\begin{abstract}
The increase in the production of energy through renewable energies and the reduced predictability of meteorological variables leads to consider reliable energy storage systems to ensure the constant supply of energy and the stabilization of the network. This paper studies four commercial energy storage systems for energy supply to an island by using photovoltaic panels and hydrokinetic turbine as primary energy sources. The technical characteristics of the energy storage systems are compared with respect to capacity shortage, autonomy storage and expected life storage, and the economic analysis is carried out. The system with li-ion batteries has 15 year expect life storage, the fuel cell based system has the highest storage autonomy $253 \mathrm{hr}$, and the pump hydro storage system has the lowest levelized cost of energy $0.178 \$ / \mathrm{kWh}$ with 7 year expect life storage.
\end{abstract}

Keywords: energy storage; hybrid system; off-grid applications; renewable energy

\section{Introduction}

The development of renewable energy with marginal costs such as solar or wind energy is achieving increasing funding in liberalized energy markets. Latin America and the Caribbean have $173.25 \mathrm{GW}$ of installed capacity in renewable energy, mainly from three primary sources, hydroelectric (159 GW), wind (12.3 $\mathrm{GW})$ and solar $(1.95 \mathrm{GW})$ developed in recent years [1], [2]. The sizing of a hybrid system and the adequate energy management from intermittent sources is a 
complex task due to the poor predictability of the climate. Several researchers have proposed methodologies, mathematical algorithms and software applications to achieve optimal sizing [3]-[5].

Energy storage systems fulfill two main functions. The first function is to store the excess energy when the load does not require it and the second is to smooth the variations in the network as a result of the intermittence of the primary sources or the starting of some equipment. Said [6] presented an overview of different electrical energy storage technologies to reduce these fluctuations.

Currently, there are several types of energy storage commercially available, used in different projects. Among them are the hydraulic pumping, batteries, compressed air, super capacitor and flywheel [7]. Evans [8] reviewed energy storage technologies, comparing parameters such as efficiency, energy capacity, energy density, execution time, capital investment costs, response time, lifespan in years and cycles, and self-discharge. This work concluded that the choice of the storage system depends on the individual requirements, such as the capacity of the system and security in the delivery of energy.

Energy storage systems represent the highest cost in the implementation of hybrid systems. In [9], the authors presented the technical economic analysis of a hybrid system composed of solar panels, hydrokinetic turbine, fuel cell and battery acid lead. The hydrogen subsystem represented $45.5 \%$ of the total cost of the hybrid system, whereas the battery bank was $24.9 \%$. Several successful models to solve optimization problems have been reviewed. A stochastic approximation algorithm (SA) was used in [10], which was based on a simultaneous perturbation gradient approximation instead of the standard Kiefer-Wolfowitz approximation. The numerical results obtained showed that the SA algorithm can be more efficient in problems of large dimensions.

An algorithm called Quantum Structure Analyzer 1.0 was presented in [11], whose operating principle was based on the Self-Organization Network by Kohonen. The algorithm was used to examine the grouping of nanostructures that are formed in a process of self-organization, technical parameters such as size, shape and spatial distribution in order to determine the characteristics of the devices. In addition, a grouping algorithm combined with a diffuse inference algorithm was used.

In data mining, the grouping of information is an important technique to create groups of similar objects within a grouping and different object between the different groupings. In [12], the authors presented an improved hybrid algorithm (IABCFCM) based on Fuzzy c-means (FCM), which used data grouping and an Artificial Bee Colony (ABC) algorithm. $\mathrm{ABC}$ is based on swarms inspired by the intelligent behavior of bees. The improved IABCFCM algorithm helped the fuzzy c-means cluster to escape from local optima and provide better experimental results in known data sets. 
The problem of optimal sizing of storage systems was investigated in [13]. The authors considered two different storage systems (batteries and hydraulic storage pumped). The solution was achieved through optimization, using a non-linear programming approach in GAMS and considering several operational constraints such as efficiency, depth of discharge, response speed in order to obtain the minimum total cost of the system. It was experimentally tested and a comparative study was carried out. Jacob [14] developed a methodology for sizing a storage system using pinch analysis. The analysis was performed through a simulation of time series of the system, where the generation has to always exceed the load for an isolated hybrid system based on renewable energies. The methodology defined the design space as feasible combinations of storage in the short, medium and long term.

Young [15] studied the sizing of a battery energy storage system (BESS), and used financial, technical and hybrid indicators. The size of the subsystem can be determined by using methods and techniques, such as probabilistic methods, analytical methods, directed, search-based methods and hybrid methods. This work concluded that the proper method for sizing the battery bank is determined by the type of application and the system size.

Commercial programs can be used for the optimal sizing of hybrid systems. HOMER is a tool widely used by researchers. Through simulations, the number of components required to satisfy the demand is determined to achieve the minimum costs of the system and operation, and to comply with the technical limitations and emissions [16].

So far the research developed has focused on the optimized size of the storage systems for the balance between operation, support and cost, since it is one of the most expensive elements of the system. This work pretends to serve as a useful guidance for selecting energy storage systems for off-grid hybrid renewable energy systems. Furthermore, it provides a techno-economic analysis of four types of storage systems that have been chosen based on the following criteria: ability to provide energy for a long time; widely used technology; 3) fully renewable technology; and 4) new energy backup technique. Economic technical optimization is achieved through the HOMER software, which uses patented "derivative free" algorithm to identify the lowest energy cost for the hybrid system.

This paper is structured as follows. After the introduction, the different energy storage systems are reviewed in Section 2. Section 3 shows the mathematical model of the components of the system. Section 4 describes the different configurations simulated. The different configurations under study are compared in technical and economic terms in Section 5. Finally, the conclusions of the paper are drawn in Section 6. 


\section{Energy Storage Systems}

In this section, the different types of energy storage systems are reviewed. The delivery of stored energy depends on the needs of the load. The different storage technologies are categorized into short, medium, and long-term storage. In Fig. 1, the duration of the download of the different storage systems in time scale is shown.

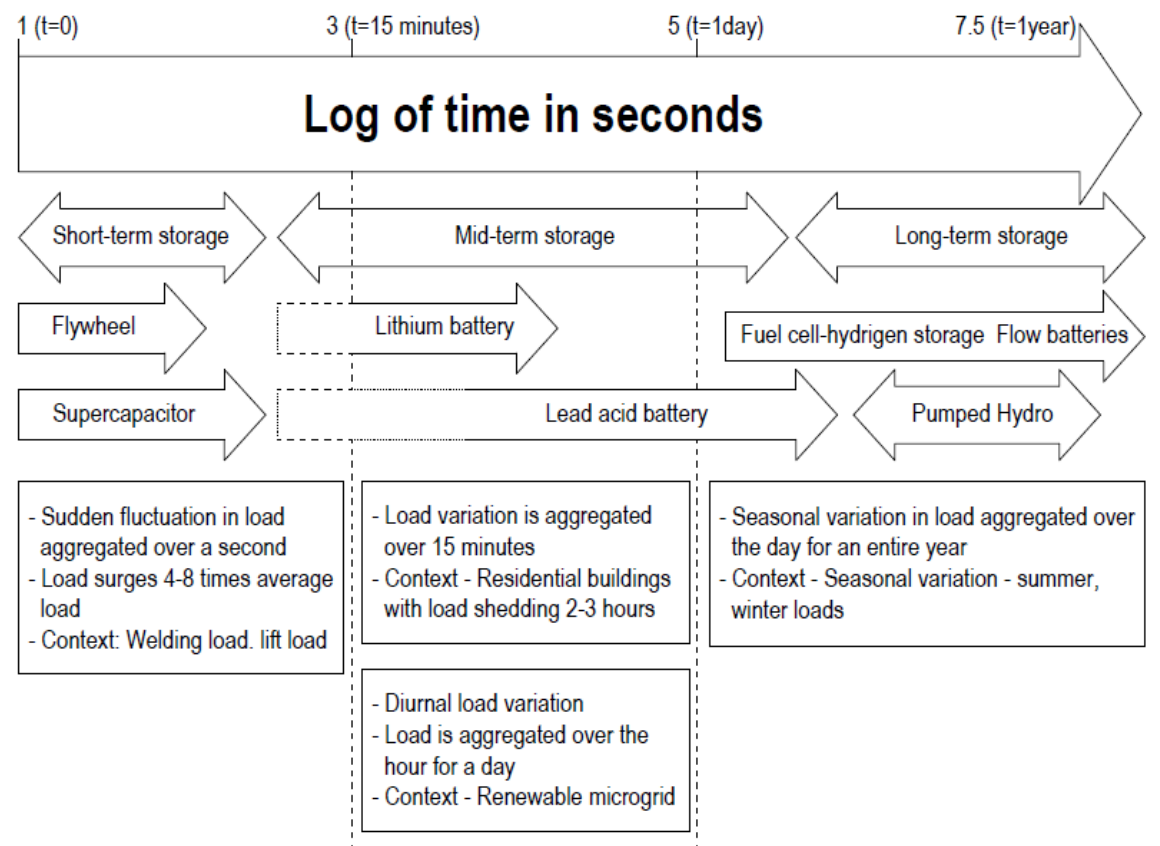

Figure 1

Energy storage technologies [14]

\subsection{Flywheel Energy Storage}

Flywheel energy storage represents an ecological option since it is made of nonhazardous base metals and carbon fibers. It uses a flywheel that rotates at very high speed. Inertia wheels store energy in its kinetic form [15]. Flywheels provide an amount of energy in a short time. The operational life is several million complete cycles of discharge, unlike batteries can reach up to 20 years of useable life [17]. The amount of energy stored is given by Equation (1).

$$
E=\frac{1}{2} I \cdot \omega^{2}
$$

Where $I$ is the inertia moment of the steering wheel and $\omega$ is the angular velocity. 


\subsection{Supercapacitor}

Supercapacitor is composed of two electrodes in parallel with a dielectric material between them. It differs from the conventional capacitor because of its high capacity and discharge current [18]. Supercapacitors can be charged and discharged quickly. The long cycle of operation without degradation makes it attractive for use. They are mainly used to start motors, actuators and electric vehicles [19].

\subsection{Lithium Battery}

Lithium battery transforms the chemical energy of its metallic lithium composites into electrical energy through oxidation and reduction reactions. The advantages offered are: $100 \%$ efficiency, the highest achieved of all types of batteries; load densities are between 90-190 Wh/kg; and low environmental impact due to their recyclable components.

The main barrier in the extended use of this type of battery is the cost due to the special packaging and the internal overload protection circuit [17]. The electrical storage capacity of a Li-ion battery is limited by the amount of lithium that can be trapped at the battery anode. The lifetime is 3,000 cycles at $80 \%$ depth of discharge, the cost is $800-1100 \$ / \mathrm{kWh}[20]$.

\subsection{Lead Acid Battery}

Lead-acid batteries are widely used in renewable energy systems and other applications. They are rechargeable batteries and are composed of an anode of metallic lead, a cathode of lead dioxide and an electrolyte of sulfuric acid solution. Among the advantages that they present are: the cost under 500-150 $\$ / \mathrm{kWh}$, simplicity in the manufacture, fast electrochemical reaction, and efficiency of $72 \%$. The main disadvantage is the use of heavy metal components, dangerous for the environment. The lifetime is limited. Several types of lead-acid batteries have been developed, such as lead antimony batteries, SLI (starting, lighting and ignition) batteries, valve-regulated lead acid batteries (VRLA), flooded lead acid batteries, lead and calcium batteries, AGM absorbed glass mats batteries, gel cells and deep cycle batteries. The last two are commonly used in renewable energy systems [21].

\subsection{Electrolyzer and Fuel Cell}

Hydrogen energy storage system is a clean technology. It is an acceptable option for remote communities that are not connected to a conventional network. There is currently a wide variety of commercially available fuel cells (FC). Proton exchange membrane(PEM) type is used for small-scale hybrid systems [22]. The 
excess energy produced by the generators feeds the electrolyzer, which is a device that generates hydrogen and oxygen from water. The produced hydrogen is stored in a tank or taken directly to the FC.

\subsection{Pumped Hydro Storage}

Pumped hydro storage (PHS) is a mature and commercially available technology. It stores and generates electricity through two water tanks at different heights, and energy produced in excess feeds a pump that sends water from a lower reservoir to an upper reservoir [23].

When the demand is greater than the generation, the water stored in the upper tank passes through a turbine that produces electrical energy. In some cases, pumping systems are based on reversible electric and hydraulic machines. The energy used to pump water from the lower reservoir is obtained by Equation (2).

$$
E_{\text {pumping }}=\frac{\rho \cdot g \cdot h \cdot V}{\eta_{p}}
$$

where $V$ is the volume of water, $h$ is the height of the upper reservoir, and $\eta_{p}$ is the pumping efficiency.

The energy supplied by the generator to the network can be obtained by Equation (3).

$$
E_{\text {generator }}=\rho \cdot g \cdot h \cdot V \cdot \eta_{g}
$$

where $\eta_{g}$ is the generator efficiency.

\section{Mathematical Model of System under Study}

The hybrid systems under study in this work use the following components: photovoltaic (PV) panels, hydrokinetic (HKT) turbine, batteries, hydrogen system (FC, FC, electrolyzer and tank), pumped hydro storage and electronic power converters. This section describes the mathematical models used to represent the behavior of these components.

\subsection{PV Panel}

Santay Island receives around 12 hours of sun a day with a high global radiation so that PV energy is a promising source to be used for electrification purposes.

For the modeling of the PV panels, polycrystalline type models CS6K-285M-FG are commercially available, which present the following characteristics: a power of $285 \mathrm{~W}$; an efficiency in standard test conditions (STC) of 17.41\%; the open circuit voltage $\left(\mathrm{V}_{\mathrm{oc}}\right)$ is $38.6 \mathrm{~V}_{\mathrm{dc}}$; the short circuit current $\left(\mathrm{I}_{\mathrm{sc}}\right)$ is $9.51 \mathrm{~A}$; the 
dimensions (mm) are 1,650-992-40 $\mathrm{mm}$; the capital cost is US\$ $300 / 285 \mathrm{Wp}$; the replacement cost is US $\$ 300 / 285 \mathrm{Wp}$; the operating and maintenance cost $\$ 0$ for not having moving parts; and the lifetime is 25 years.

The estimation of the maximum power of the PV generator is an important parameter to consider in the system. The maximum output power of the PV module can be calculated under operating conditions as follows:

$$
P_{P V}=f_{P V} * Y_{P V} * \frac{I_{T}}{I_{S}}
$$

where $f_{P V}$ is the reduction factor, which takes into account the losses due to high temperatures, dirt, wiring, that reduce the performance of the panel; $Y_{P V}$ is the rated capacity of the PV array $(\mathrm{kW}) ; I_{T}$ is the total incident radiation on the panel surface $\left(\mathrm{kWh} / \mathrm{m}^{2}\right)$; and $I_{S}$ is $1000 \mathrm{~W} / \mathrm{m}^{2}$.

\subsection{HKT Turbine}

The energy from the flow of water that surrounds the island can be exploited by a HKT turbine to be converted into electrical energy. In this work, a $5 \mathrm{~kW}$ smart monofloat turbine from the manufacturer Smart hydro power was used [24], which present the following characteristics: the dimension are 2640-1120-1120 $\mathrm{mm}$; the rotational speed is 90 to $230 \mathrm{rpm}$; the weight is $380 \mathrm{~kg}$; the number of rotor blades is 3 ; the cost of capital is $\$ 11179$; and the cost of operation and maintenance is 100 \$/year. The energy generated by the HKT turbine $\left(E_{H K T}\right)$ can be calculated as:

$$
E_{H K T}=\frac{1}{2} * \rho_{W} * A * v^{3} * C_{p, H} * \eta_{H K T} * t
$$

where $\rho_{W}$ is the water density in $\mathrm{kg} / \mathrm{m}^{3} ; \eta_{H K T}$ is the combined HKT-generator efficiency; $C_{p, H}$ is the HKT performance coefficient; $v$ is the water flow velocity in $\mathrm{m} / \mathrm{s} ; A$ is the HKT area in $\mathrm{m}^{2}$; and $t$ is the time in $\mathrm{s}$.

\subsection{Batteries}

Battery consists of electrochemical cells that can convert chemical energy into electrical energy. The energy produced in excess can be stored in the batteries, which is used when there is a peak consumption that cannot be supplied by the renewable generation.

The state-of-charge (SOC) of the battery for the charging and discharging modes can be calculated by [25]:

$$
\begin{gathered}
\operatorname{SOC}(t)=\operatorname{SOC}(t-1)+\frac{E_{\text {bat }}(t) * \eta_{c b a t}}{P_{b a t}} * 100 \\
\operatorname{SOC}(t)=\operatorname{SOC}(t-1)+\frac{E_{b a t}(t) * \eta_{\text {dbat }}}{P_{\text {bat }}} * 100
\end{gathered}
$$


where $\operatorname{SOC}(t)$ is the state of charge at time $t ; P_{\text {bat }}$ is the nominal capacity of the battery; $E_{b a t}$ is the power exchange during the time step $\Delta t$; and $\eta_{c b a t}, \eta_{\text {dbat }}$ are the battery charge and discharge efficiency, respectively.

\subsection{FC}

In this work, a PEM FC is considered for the hydrogen energy storage system. FC uses hydrogen to produce DC electrical energy. PEM FC is one of the best options for distributed generation, since it has advantages such as its low operating temperature, high-power density, longevity, specific power [26].

Different works indicate an initial capital cost of the FC system from $\$ 2,000 / \mathrm{kW}$ to $\$ 6.000 / \mathrm{kW}$. The installation, operational costs and replacement are estimated depending on the power of the system at $\$ 3,000, \$ 0.080 / \mathrm{h}$ and $\$ 2,500$ respectively [9].

The electric power output from the FC, $P_{f c}$, can be calculated as follow [27]:

$$
P_{f C}=U_{\text {Stack }} \times I=U_{S C} \times N_{C E L L S} \times I
$$

The hydrogen consumption of the FC in one hour can be calculated from the FC power as follows:

$$
q_{H_{2}}^{\text {con }}=\frac{P_{f c}}{E_{\text {low }, H_{2}} * \eta_{\text {therm }} * U_{f} * \eta_{f c}}
$$

where $P_{f c}$ is the output power supplied by the FC; $U_{S C}$ is the average single cell voltage; $I$ is the current; $E_{\text {low }, H 2}$ is the lower heating value of hydrogen $\left(E_{\text {low }, H 2}\right.$ $=33.35 \mathrm{kWh} / \mathrm{kg}) ; \eta_{\text {therm }}$ is the thermodynamic efficiency $(0.98$ at $298 \mathrm{~K}) ; U_{f}$ is the fuel utilization efficiency and $\eta_{f c}$ is the FC efficiency.

\subsection{Electrolyzer}

An electrolyzer converts DC electrical energy into chemical energy stored in hydrogen. An electric current drives the decomposition of water, which is fed to the anode, into hydrogen and oxygen. The occurring reactions in a PEM electrolyzer are:

$$
\begin{aligned}
& \text { anode } \mathrm{H}_{2} \mathrm{O} \rightarrow 2 \mathrm{H}^{+}+1 / 2 \mathrm{O}_{2}+2 e^{-} \\
& \text {cathode } 2 \mathrm{H}^{+}+2 e^{-} \rightarrow \mathrm{H}_{2}
\end{aligned}
$$

The advantages of PEM electrolyzer are: high voltage efficiency, high current densities, good partial load range, high gas purity, rapid system response. PEM electrolyzers have a conversion efficiency of 40 to $60 \%$ similar to alkaline electrolyzers, due to the membrane and noble metals the PEM are more expensive, although promising studies consider an $85 \%$ efficiency [28]. 
The electrical power consumed by the electrolyzer can be calculated as follow:

$$
P_{E}=\frac{\dot{\mathrm{m}}_{H_{2}} \times H H V_{H_{2}}}{\eta_{E}}
$$

where, $P_{E}$ is the power consumption of the element; $\eta_{E}$ is the electrolyzer efficiency; $\dot{\mathrm{m}}_{\mathrm{H}_{2}}$ is the produced hydrogen mass flow rate $(\mathrm{kg} / \mathrm{s})$; and $H H V_{\mathrm{H}_{2}}$ is the gross calorific value $(\mathrm{MJ} / \mathrm{kg})$.

\subsection{Hydrogen Storage Tank}

The hydrogen generated by the electrolyzer needs to be stored in a tank to supply the FC. The price of a tank with $1 \mathrm{~kg}$ of hydrogen capacity is estimated at $\$ 1,500$. The replacement costs are estimated at $\$ 1,500$ per $\mathrm{kg}$ similar to studies performed. The useful life of the hydrogen tank is estimated at 25 years [9].The tank autonomy can be calculated using the following equation [29]:

$$
A_{\text {htank }}=\frac{Y_{\text {htank }} \times L H V_{H_{2}}(24 h / d)}{L_{\text {prim, ave }}(3.6 \mathrm{MJ} / \mathrm{kWh})}
$$

where $Y_{\text {htank }}$ is the capacity of the hydrogen tank $(\mathrm{kg}) ; L H V_{H_{2}}$ is the energy content of hydrogen; and $L_{\text {prim, ave }}$ is the average primary load $(\mathrm{kWh} / \mathrm{kg})$.

\subsection{Pumped Hydro}

Pumped hydro system allows storing water in a tank at a certain height when there is excess energy. It converts the potential energy into electricity by a turbine when the energy generation is required.

In this work a generic $245 \mathrm{kWh}$ pumped hydro system was used. It presents a nominal capacity of. 1,059.000 Ah.

The energy storage capacity can be calculated as follow [29]:

$$
E[J]=9.81 P_{\text {water }} \times V_{\text {res }} \times h_{\text {head }} \times \eta
$$

where $E$ is the energy stored $(\mathrm{J}) ; P_{\text {water }}$ is the density of water $(1000 \mathrm{~kg} / \mathrm{m} 3) ; V_{\text {res }}$ is the volume of the reservoir $\left(\mathrm{m}^{3}\right) ; h_{\text {head }}$ is the head height in meters; and $\eta$ is the efficiency.

\subsection{Electronic Power Converters}

All configurations in this work need DC/AC converters for the connection to the AC network. The connection between the DC bus and the loads is made by a DC/AC converter. The converters must respond to several challenges, in terms of voltage ratio, energy efficiency, output current ripple, cost and reliability in case of power switch fault-tolerance. For this work, a range of inverter $(0-20 \mathrm{~kW})$ with efficiency of $95 \%$ and a useful life of 15 years is considered. The installation cost 
is $\$ 300 / \mathrm{kW}$ and the replacement cost is equal to the initial capital. The cost of O\&M is zero for inverter [9].

\section{Studied Configurations}

The hybrid systems under study in this work are designed to satisfy the demand of the inhabitants of Santay Island. The island is located in the Gulf of Guayaquil, $800 \mathrm{~m}$ from the city of Guayaquil, with an area of $21.79 \mathrm{~km}^{2}$. This island has a population of 56 families living in 46 houses. The consumption load is characterized by the habits of the residents of the coastal area of Ecuador [30] with a minimum consumption $(3.1 \mathrm{~kW})$, average consumption $(4.18 \mathrm{~kW})$ and maximum consumption $(5.6 \mathrm{~kW})$. The renewable energy resources (radiation solar and river speed) are studied below.

\subsection{Renewable Energy Resources}

The abundant solar radiation $\left(2^{\circ} 12.5^{\prime} \mathrm{S}, 79^{\circ} 52.2^{\prime} \mathrm{W}\right)$ is shown in Figure 2. The data were obtained through the HOMER software. The annual average is 4,630 $\mathrm{kWh} / \mathrm{m}^{2} /$ day [29].

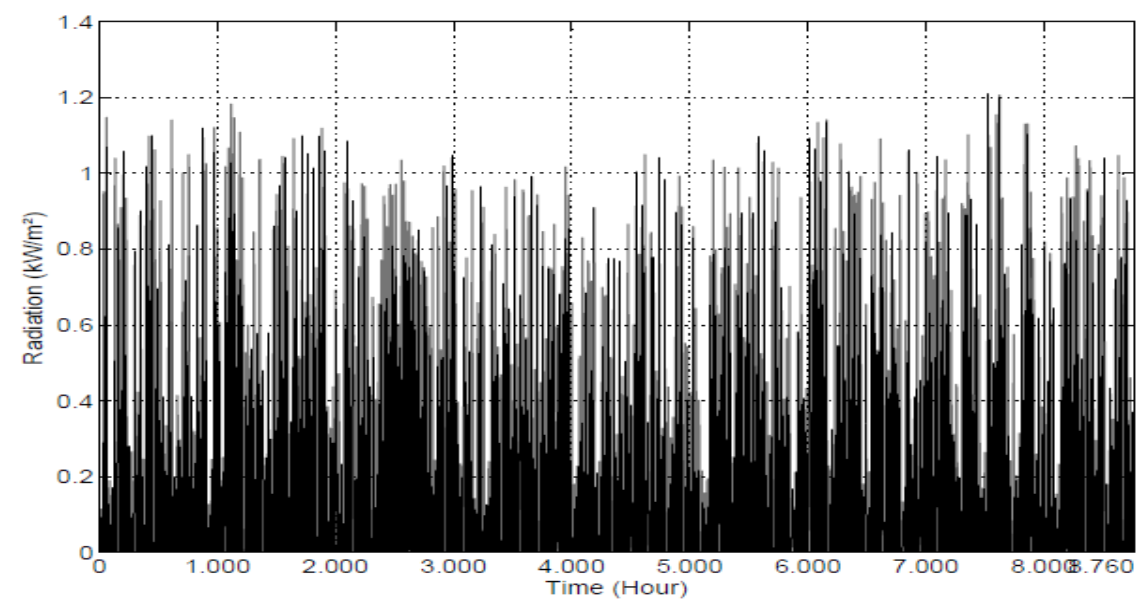

Figure 2

Radiation solar annual

The kinetic energy of the river flow is exploited. The annual river velocity data is shown in Figure 3. These data are provided by the Oceanographic Institute of the Ecuadorian Navy (INOCAR) [31]. The highest recorded speed is $2.26 \mathrm{~m} / \mathrm{s}$, the slow speed is $0.31 \mathrm{~m} / \mathrm{s}$ and the average is $1.39 \mathrm{~m} / \mathrm{s}$. To carry out the simulation, the monthly average values are taken. 


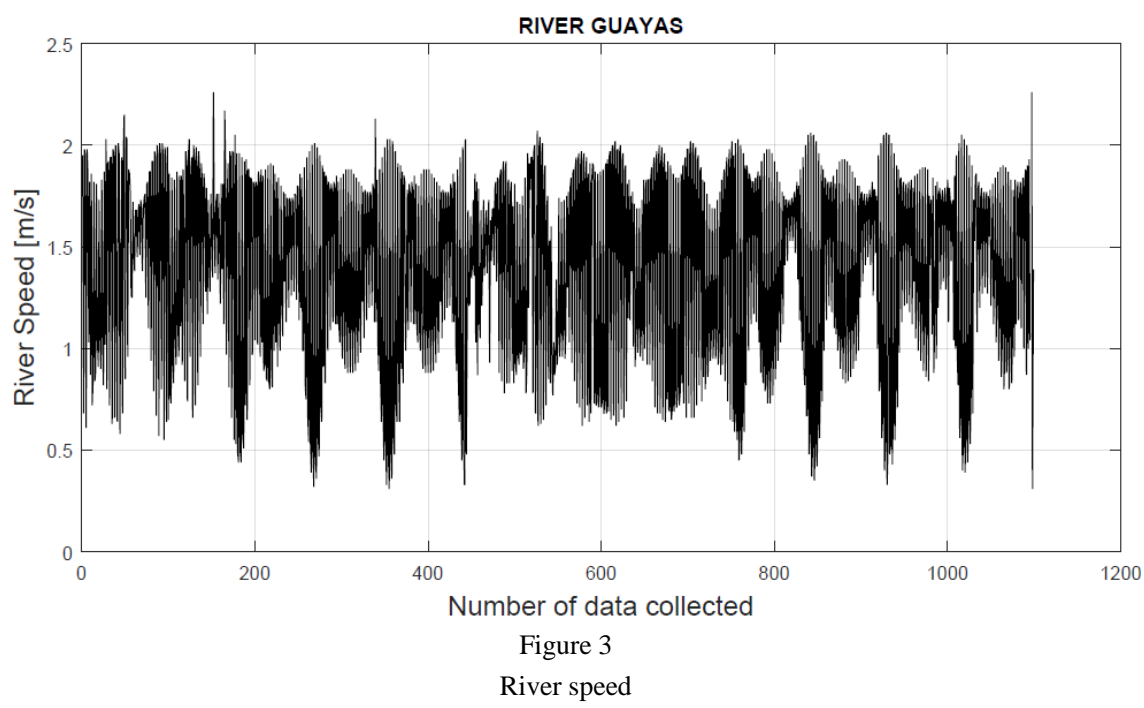

\subsection{Systems under Study}

Four hybrid systems have been studied. In all of them, PV panels and HKT are used as primary energy sources, the ESS with little capacity to provide energy for long time are not considered in the study. The studied configurations have been chosen based on widely used energy storage: 1) lead acid and 2) lithium batteries commonly used; 3) hydrogen system (electrolyzer, hydrogen tank and FC) is a totally renewable technology that is being used despite its high costs; 4) pumped hydro is a promising technology with a high application capacity.

The optimal configuration of each hybrid system under study is obtained by HOMER. The program carries out hundreds or even thousands of configurations to achieve the optimum sizing of the hybrid system. Each system is evaluated by four parameters: 1) lower initial capital; 2) total net present cost, which is the present value of all system costs over the useful life; 3) cost of energy, which is the average cost per $\mathrm{kWh}$ produced by the system; and 4) maximum capacity shortage or maximum allowable value of the capacity shortage fraction.

\subsubsection{PV, HKT, Lithium Battery-based Hybrid System}

Figure 4 shows the hybrid system under study. The resulting optimal sizing is composed of a PV array $(42 \mathrm{~kW}), 3$ HKT turbines $(15 \mathrm{~kW})$, a $1 \mathrm{kWh}$ Li-Ion battery bank (50 units) and a DC/AC power converter $(10 \mathrm{~kW})$.

Table 1 shows the technical characteristics of the system. The simulation provided the following results: the initial capital of the system is $\$ 48,400$, TNPC is $\$ 96,804$, LCOE is $0.178 \$ / \mathrm{kWh}$, the capacity shortage is $0.29 \%$ and the electrical 
load that the system is unable to serve (Unmed Electric Load) is $72.2 \mathrm{kWh} / \mathrm{yr}$ $(0.20 \%)$ of total load.

The model used is a generic $1 \mathrm{kWh}$ li-ion battery, which has a nominal voltage of $3.7 \mathrm{~V}$, a nominal capacity of $1.02 \mathrm{kWh}$, a maximum capacity of $276 \mathrm{Ah}$, a capacity ratio of 1 , a rate constant of $1(1 / \mathrm{h}), 8 \%$ in other round -trip losses, and the effective series resistance is $0.00036 \mathrm{ohms}$.

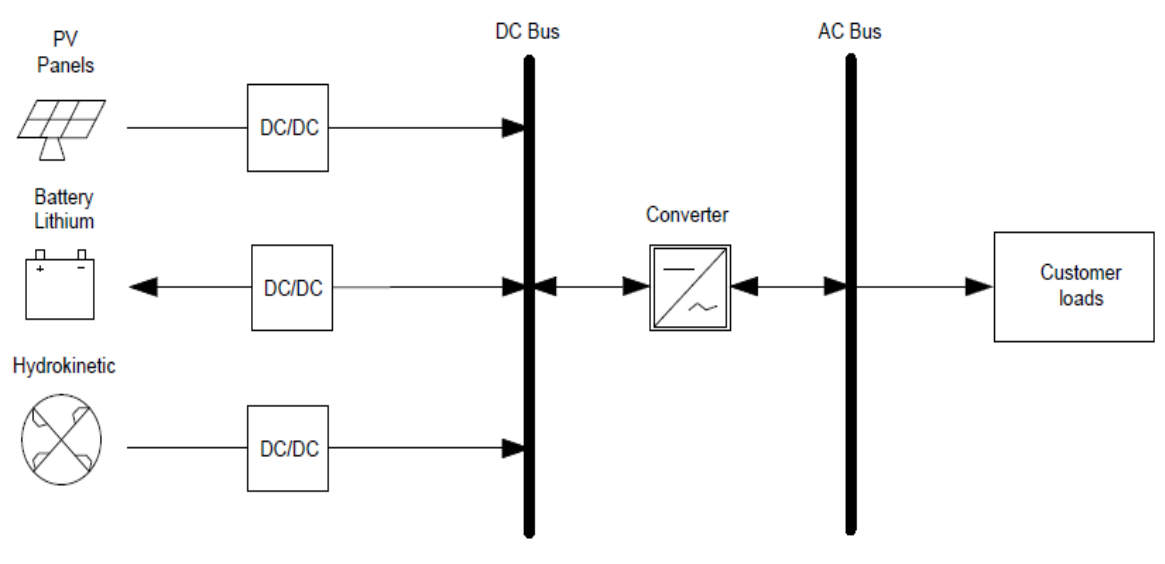

Figure 4

Configuration of the PV, HKT, Lithium Battery-based hybrid system

Table 1

Technical characteristics of the PV, HKT, Lithium Battery-based hybrid system

\begin{tabular}{|c|c|c|c|}
\hline Components & $\mathrm{PV}$ & HKT & Converter \\
\hline Rated Capacity (kW) & 42 & 15 & 10 \\
\hline Mean Output (kW) & 6.53 & 3.38 & 3.95 \\
\hline Maximum Output (kW) & 34.5 & 5.98 & 8.54 \\
\hline Capacity Factor (\%) & 15.6 & 22.5 & 39.5 \\
\hline Total Production $(\mathrm{kWh} / \mathrm{yr})$ & 57,236 & 29,547 & $\begin{array}{cl}---- \\
\end{array}$ \\
\hline PV Penetration $(\%)$ & 165 & 85.4 & ----- \\
\hline Hours of Operation & 4,189 & 8,760 & 8760 \\
\hline
\end{tabular}

The per year operating cost is $\$ 2,435$, the levelized costs for the PV and HKT are $\$ 0.0149$ and $\$ 0.065$ per $\$ / \mathrm{kWh}$, respectively. The energy stored by the batteries is $6,592 \mathrm{kWh} / \mathrm{yr}$, the energy consumed out is $6,063 \mathrm{kWh} / \mathrm{yr}$, the storage depletion (the difference between the battery state of charge at the start of the year and at the end of the year) is $6.28 \mathrm{kWh} / \mathrm{yr}$ and the losses are $565 \mathrm{kWh} / \mathrm{yr}$, the lifetime throughput 94,587 $\mathrm{kWh}$ and expected life $15 \mathrm{yr}$.

The components that have a higher cost of capital are batteries and PV panels, with $\$ 30,000$ and $\$ 13,440$ respectively. The component with the highest replacement cost is the battery bank with $\$ 16,847$. The cost per operation and 
maintenance of the battery is $\$ 7,876$. The total cost of the system is $\$ 96,803$. It is composed of the following items: capital $\$ 58,440$, replacement $\$ 32,260$, O\&M $\$ 12,601$, salvage $\$ 6,498$.

\subsubsection{PV, HKT, Lead Acid Battery-based Hybrid System}

Figure 5 shows the proposed hybrid system, which is formed by a PVarray (45 $\mathrm{kW}), 3$ units of HKT turbines $(15 \mathrm{~kW})$, a battery bank of 55 units $(1 \mathrm{kWh})$ and a DC/AC converter $(10 \mathrm{~kW})$. The energy storage system is composed by a generic 1 $\mathrm{kWh}$ lead-acid battery, which has a nominal voltage of $12 \mathrm{~V}$, a maximum charge current of $16.7 \mathrm{~A}$, a capacity ratio of 0.403 , a rate constant of $0.82716 \mathrm{1} / \mathrm{h}$ and a maximum capacity of $83.4 \mathrm{Ah}$.

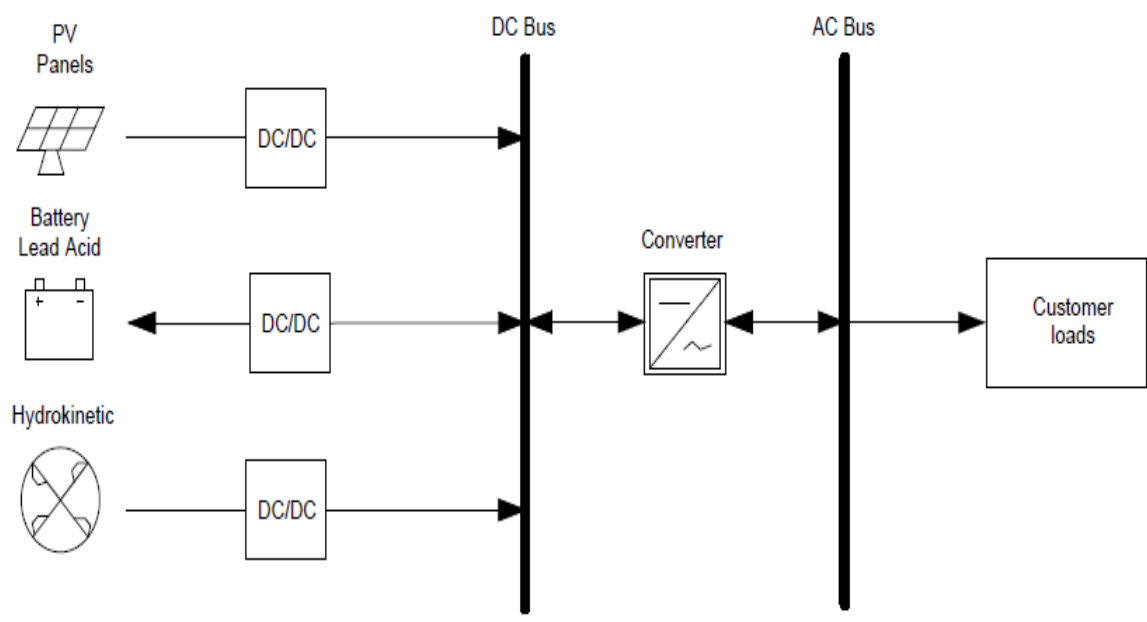

Figure 5

Configuration of the PV, HKT, Lithium Battery-based hybrid system

The initial capital cost of the system under study is $\$ 51,900$, the TNPC is $\$ 106,854$, the LCOE is $0.196 \$ / \mathrm{kWh}$, the capacity shortage is $0.232 \%$ and the unmed electric load is $57.7 \mathrm{kWh} / \mathrm{yr}(0.16 \%)$ of total load. The per year operating cost is $\$ 3,489$, the levelized costs for the PV and HKT are \$0.0149 and \$0.0605 per $\$ / \mathrm{kWh}$, respectively.

The excess energy stored by the batteries is $7,530 \mathrm{kWh} / \mathrm{yr}$, the output energy is $6,029 \mathrm{kWh} / \mathrm{yr}$, the storage depletion is $5.97 \mathrm{kWh} / \mathrm{yr}$ and the losses is 1,507 $\mathrm{kWh} / \mathrm{yr}$, the lifetime throughput $60,000 \mathrm{kWh}$ and the expected life $8.90 \mathrm{yr}$.

The components that have a higher capital cost are the batteries and PV panels with $\$ 22,500$ and $\$ 14,400$ respectively. The component with the highest replacement cost is the battery bank with $\$ 27,321$, the same happens with the cost per operation and maintenance, $\$ 11,814$. The total cost of the system is $\$ 106,853$ (capital \$51,900, replacement \$42,734, O\&M \$16,540, salvage \$4,320). 
The optimization results given by HOMER according to the specifications are shown in Table 2.

Table 2

Technical characteristics of the PV, HKT, lead acid battery-based hybrid system

\begin{tabular}{lrrr}
\hline Components & PV & HKT & \multicolumn{2}{c}{ Converter } \\
\hline Rated Capacity $(\mathrm{kW})$ & 45 & 15 & 10 \\
\hline Mean Output $(\mathrm{kW})$ & 7 & 3.38 & 3.95 \\
\hline Maximum Output $(\mathrm{kW})$ & 37 & 5.98 & 8.54 \\
\hline Capacity Factor $(\%)$ & 15.6 & 22.5 & 39.5 \\
\hline Total Production $(\mathrm{kWh} / \mathrm{yr})$ & 61,324 & 29,547 & ----- \\
\hline PV Penetration $(\%)$ & 177 & 85.4 & ---- \\
\hline Hours of Operation & 4,189 & 8,760 & 8760 \\
\hline
\end{tabular}

\subsubsection{PV, HKT, Hydrogen-based Hybrid System}

The architecture of the proposed system is presented in Figure 6, where the system is composed of a PV array (40 kW), HKT turbines $(15 \mathrm{~W})$, a FC $(6 \mathrm{~kW})$, an electrolyzer $(10 \mathrm{~kW})$, a hydrogen tank $(30 \mathrm{~kg})$ and a DC/AC power converter (10 $\mathrm{kW})$. The optimization results given by HOMER according to the specifications are shown in Table 3.

The simulation provided the following results: the initial capital of the system is $\$ 110,800$, the TNPC is $\$ 189,640$, the LCOE is $0.348 \$ / \mathrm{kWh}$, the operating cost is $\$ 5,005$, the capacity shortage is $0.27 \%$ and the unmed electric load is $62.6 \mathrm{kWh} / \mathrm{yr}$ $(0.18 \%)$ of total load.

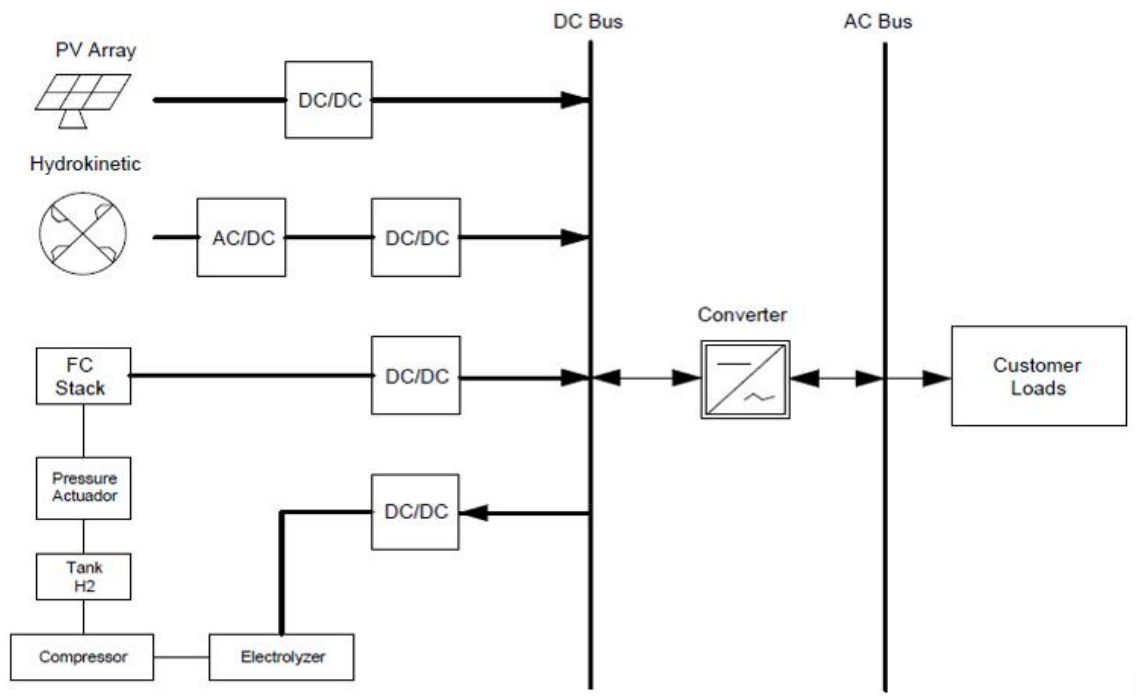

Figure 6

Configuration of the PV, HKT, hydrogen-based hybrid system 
The levelized costs for the PV and HKT are $\$ 0.0149$ and $\$ 0.0605$ per $\$ / \mathrm{kWh}$, respectively. The hydrogen subsystem presents the following results: electrical production $6058 \mathrm{kWh} / \mathrm{yr}$, hours of operation 3,805 hrs/yr, numbers of starts 623 starts/yr, fixed generation cost $1.05 \$ / \mathrm{hr}$, fuel consumption $363 \mathrm{~kg}$ and operational life $105 \mathrm{yr}$.

In the third system under study, the capital costs of hydrogen tank, electrolyzer and FC are the highest $\$ 45,000, \$ 20,000$ and $\$ 18,000$ respectively. The FC has the highest replacement cost and O\&M with $\$ 20,030$ and $\$ 35,962$, respectively.

The HKT has the second highest cost of O\&M with $\$ 4,725$, while the cost of O\&M for the hydrogen tank and PV is zero due to having no moving parts or consumables. The total cost of the system is $\$ 189,639$, which consists of the following items: capital $\$ 110,800$, replacement $\$ 43,867$, O\&M $\$ 43,838$, salvage $\$ 8,866$.

Table 3

Technical characteristics of the PV, HKT, hydrogen-based hybrid system

\begin{tabular}{lrrrrrr}
\hline Components & PV & \multicolumn{1}{c}{ HKT } & FC & Electrolyzer & \multicolumn{2}{c}{ Converter } \\
\hline Rated Capacity $(\mathrm{kW})$ & 40 & 15 & 6 & 10 & 10 \\
\hline Mean Output $(\mathrm{kW})$ & 6.22 & 3.38 & 1.59 & 2.07 & 3.95 \\
\hline Maximum Output $(\mathrm{kW})$ & 32.9 & 5.98 & 6 & $0.215(\mathrm{~kg} / \mathrm{hr})$ & 8.54 \\
\hline Capacity Factor $(\%)$ & 15.6 & 22.5 & 11.1 & 19.5 & 38.9 \\
\hline Production $(\mathrm{kWh} / \mathrm{yr})$ & 54,510 & 29,572 & 6,058 & $369(\mathrm{~kg} / \mathrm{yr})$ & ----- \\
\hline Penetration $(\%)$ & 157 & 85.4 & ----- & ---- & ----- \\
\hline Operation $(\mathrm{hr} / \mathrm{yr})$ & 4,189 & 8,760 & 3,805 & 3,308 & 8760 \\
\hline
\end{tabular}

\subsubsection{PV, HKT, Pumped Hydro Storage-based Hybrid System}

The pumped hydro has a reservoir that can store a capacity of $1000 \mathrm{~m}^{3}$ of water, which can be discharged over 12 hours. The system under study is shown in Figure 7 . The resulting components are a PV array $(30 \mathrm{~kW})$, HKT turbines (15 $\mathrm{kW})$, a pump hydro $(245 \mathrm{kWh})$ and a DC/AC power converter $(10 \mathrm{~kW})$. The pumped hydro has a nominal voltage of $240 \mathrm{~V}$, a maximum charge current of 91.6 A, a maximum discharge current of $91.6 \mathrm{~A}$ and the generator efficiency is $90 \%$. 


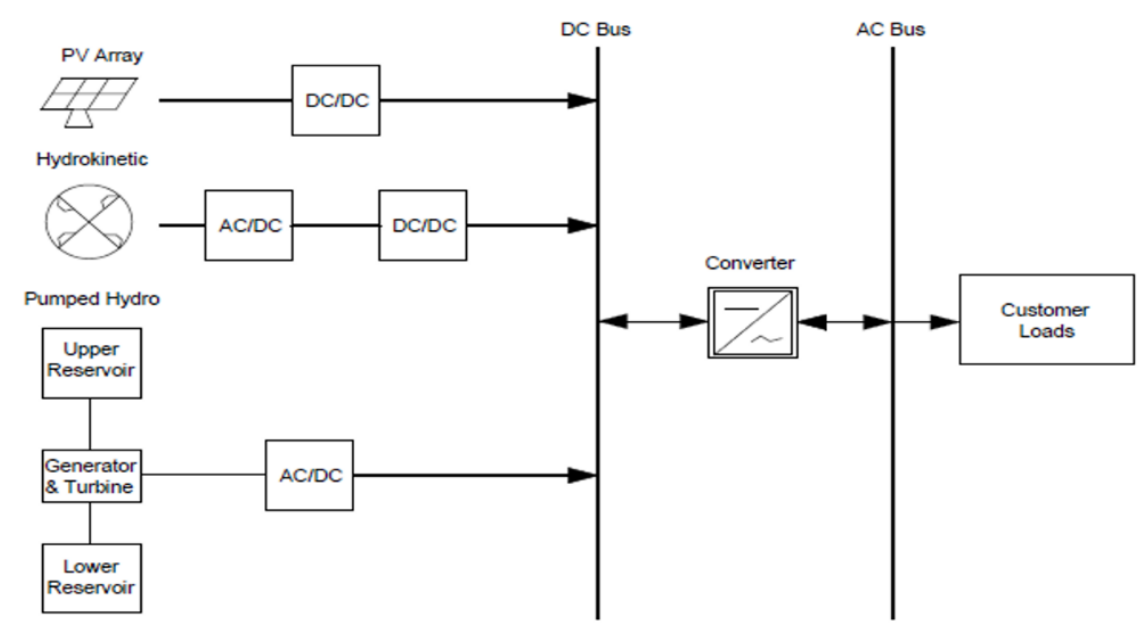

Figure 7

Configuration of the PV, HKT, pumped hydro storage-based hybrid system

Table 4 shows the parameters of system under study. The initial capital cost of the system is $\$ 42,600$, the TNPC is $\$ 86,996$, the LCOE is $\$ 0.159 / \mathrm{kWh}$, the capacity shortage is $0.04 \%$ and the unmed electric load is $10.4 \mathrm{kWh} / \mathrm{yr}(0.02 \%)$ of total load. The per year operating cost is $\$ 2,818$, the levelized costs for the PV and HKT are $\$ 0.0149$ and $\$ 0.0605$ per $\$ / \mathrm{kWh}$, respectively.

The excess energy stored by pumped hydro is $12,540 \mathrm{kWh} / \mathrm{yr}$, the output energy is $10,178 \mathrm{kWh} / \mathrm{yr}$, the storage depletion is $23.5 \mathrm{kWh} / \mathrm{yr}$, the losses is $2,385 \mathrm{kWh} / \mathrm{yr}$, the lifetime throughput $79,164 \mathrm{kWh}$ and the expected life is $7 \mathrm{yr}$.

The components that have a higher capital cost are the pumped hydro and the PV panels with $\$ 22,000$ and $\$ 9,600$, respectively. The component with the highest replacement cost is the HKT turbine with $\$ 9,152$, while the largest cost per operation and maintenance is the pumped hydro with $\$ 31,504$. The total cost of the system is $\$ 86,995$ (capital $\$ 42,600$, replacement $\$ 1,733$, O\&M $\$ 34,655$, salvage $\$ 1,993)$.

Table 4

Technical characteristics of the PV, HKT, pumped hydro storage-based hybrid system

\begin{tabular}{|c|c|c|c|}
\hline Components & PV & HKT & Converter \\
\hline Rated Capacity (kW) & 30 & 15 & 10 \\
\hline Mean Output (kW) & 4.67 & 3.38 & 3.95 \\
\hline Maximum Output (kW) & 24.7 & 5.98 & 8.54 \\
\hline Capacity Factor (\%) & 15.6 & 22.5 & 39.5 \\
\hline Total Production (kWh/yr) & 40,883 & 29,572 & ----- \\
\hline PV Penetration $(\%)$ & 118 & 85.4 & ----- \\
\hline Hours of Operation & 4,189 & 8,760 & 8760 \\
\hline
\end{tabular}




\section{Comparative Study}

\subsection{Economic Parameters}

The economic feasibility of the proposed system is performed taking into account five parameters: 1) initial capital cost, which is the total installed cost of the components at the beginning of the project; 2) TNPC; 3) capacity shortage; 4) levelized cost of energy (LCOE); and 5) annualized maintenance, operating and replacement cost. With these parameters, HOMER determines the optimal system. Each of the parameters and the equations for its calculation are presented in this work.

\subsection{TNPC}

The TNPC of a system during its useful life is defined as the present value of all costs incurred throughout life, less the present value of all the income obtained during its operation. It incorporates operating and maintenance (O\&M) costs, fuel costs, emission penalties and component replacement costs, minus the cost of rescuing each component. TNPC is the main economic indicator of HOMER [29].

The TNPC can be calculated as follows:

$$
\begin{aligned}
& C_{T P N C}=\frac{C_{\text {ann }, \text { tot }}}{\operatorname{CRF}\left(i, R_{\text {proj }}\right)} \\
& C R F_{(i, N)}=\frac{i(1+i)^{N}}{(1+i)^{N}-1}
\end{aligned}
$$

where $C_{a n n, t o t}$ is the total annual cost ( $\left.\$ / \mathrm{yr}\right) ; C R F$ is the capital recovery factor; $I$ is the interest rate (\%); and $R_{\text {proj }}$ is the project lifetime $(N)$.

\subsection{Capacity Shortage}

The maximum annual capacity shortage is the maximum allowable value of the capacity shortage fraction, which is the total capacity shortage divided by the total electric load. HOMER considers infeasible (or unacceptable) any system with a higher value of the capacity shortage fraction. Allowing some capacity shortage can change the results dramatically in some cases. This might happen if a very high peak occurs for a very short time [32].

\subsection{Levelized Cost of Energy (LCOE)}

The levelized cost of energy (LCOE) is defined as the average cost per $\mathrm{kWh}$ of useful electrical energy produced by the system. This provides a way to compare the total energy cost for each specific electrification scenario that is being considered. The result is achieved dividing the annualized cost of electricity 
produced by the total electric load served. The LCOE is calculated by equation (15).

$$
L C O E=\frac{L C C}{\sum_{j=1}^{N} \cdot\left(\frac{E_{G E N}(j)}{(1+d)^{j}}\right)}
$$

where $L C C$ is the life cycle cost; and $E_{G E N}$ represents the cost of the life cycle of the energy produced by the proposed system in the given year $j$ [29].

\subsection{Annualized Maintenance, Operating and Replacement Cost}

The annual cost of operating and maintenance increases with the operating time of the system. The cost can be determined by equation (16), while the annualized cost is determined by equation (17).

$$
\begin{gathered}
C_{O P}(j)=C_{o}(j)+C_{m}(j)+C_{r}(j) \\
A V_{o p}=\left(\frac{d(1+d)^{j}}{(1+d)^{j-1}}\right) \cdot\left(\sum_{j=1}^{N} \frac{C_{o p}(j)}{(1+d)^{n}}\right)
\end{gathered}
$$

where $C_{O}$ isthe operational cost of any component of the energy system in the year $j ; C_{m}$ is the maintenance cost of any component of the energy system incurred in the year $j$; and $C_{r}$ is the replacement cost for any system component in the year $j$.

\subsection{Results and Discussion}

Table 5 shows the results of all the hybrid systems under study obtained from HOMER. The comparative study is performed by analyzing the differences in economic parameters and technical parameters(capacity shortage, renewable production, autonomy storage, annual throughput storage and expected life storage) of each of the systems under study[29].

The PV/HKT/pump hydro configuration achieves the best results in the LCOE with $0.159 \$ / \mathrm{kWh}$, the TNPC with $\$ 86,996$, the operating cost with $\$ 2,818$, the initial capital with $\$ 42,600$. The capacity shortage (\%) is only $0.04 \%$ with 14.3 $\mathrm{kWh} / \mathrm{yr}$, which ensures the constant supply of energy, and the autonomy storage is 64.3 hours. This configuration presents the smallest PV system $(30 \mathrm{~kW})$, and the production of renewable energy is $60,597 \mathrm{kWh}$.

Table 5

Economic results of simulation

\begin{tabular}{lrrrrr}
\hline \multirow{2}{*}{ Systems } & \multicolumn{2}{l}{$\begin{array}{l}\text { PV/HKT/B } \\
\text { LITIO }\end{array}$} & $\begin{array}{l}\text { PV/HKT/ } \\
\text { B LEAD } \\
\end{array}$ & ACID & \multicolumn{2}{l}{$\begin{array}{l}\text { PV/HKT/F } \\
\text { PV/HKT/PUM } \\
\text { P HYDRO }\end{array}$} \\
\hline LCOE $(\$)$ & 0.17 & 0.19 & 0.34 & 0.15 \\
\hline TNPC $(\$)$ & 96,804 & 106,854 & 189,640 & 86,996 \\
\hline
\end{tabular}




\begin{tabular}{lrrrr}
\hline Operating cost $(\$)$ & 2,435 & 3,489 & 5,005 & 2,818 \\
\hline Initial capital $(\$)$ & 58,440 & 51,900 & 110,800 & 42,600 \\
\hline Capital Cost PV (\$) & 13,440 & 14,400 & 12,800 & 9,600 \\
\hline Capacity Shortage (\%) & 0.29 & 0.23 & 0.27 & 0.04 \\
\hline Autonomy Storage (h) & 9 & 11.4 & 253 & 64.3 \\
\hline $\begin{array}{l}\text { Annual Throughput Storage } \\
(\mathrm{kWh})\end{array}$ & 6,285 & 6,741 & ---- & 11,309 \\
\hline Expected life Storage $(\mathrm{yr})$ & 15 & 8.9 & 10.5 & 7 \\
\hline
\end{tabular}

The annual discharge of the energy storage systems under study is illustrated in Figure 9.
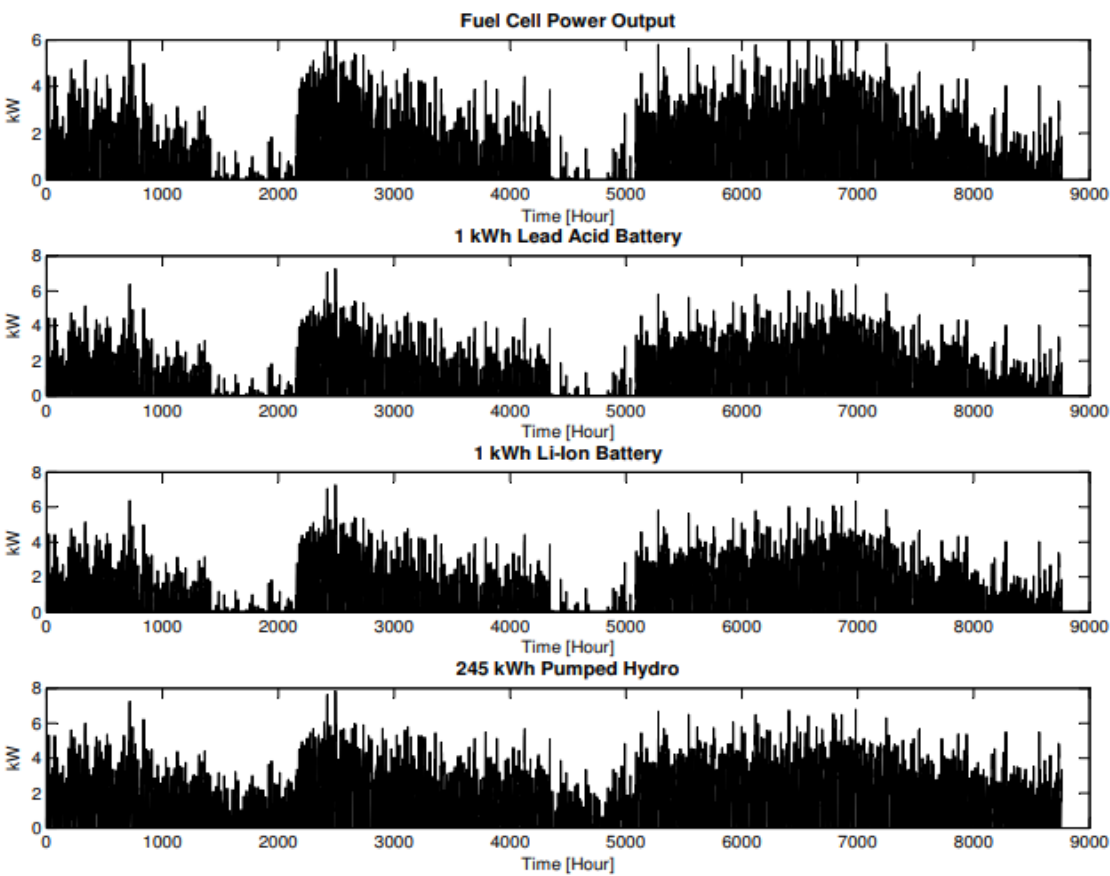

Figure 9

Annual discharge of the energy storage systems

The maximum discharge values of the FC, lead acid battery, lithium battery and pumped hydro are $6 \mathrm{~kW}, 7.26 \mathrm{~kW}, 7.26 \mathrm{~kW}$ and $7.84 \mathrm{~kW}$, respectively. The total power provided by each of the energy storage system for a year is $6,056 \mathrm{~kW}$ (FC), $6,029 \mathrm{~kW}$ (lead acid), 6,033 kW (li-ion), and 10,178 kW (pumped hydro).

Figure 10 shows the state of charge of the three energy storage system. The battery of lead acid has a discharge of $40 \%$ which promotes the increase of the system useful life. The maximum discharge is $22.5 \%$ for the battery Li-Ion, while 
the pumped hydro system delivers all the energy stored in the tank at the end of January due to the lower renewable generation.
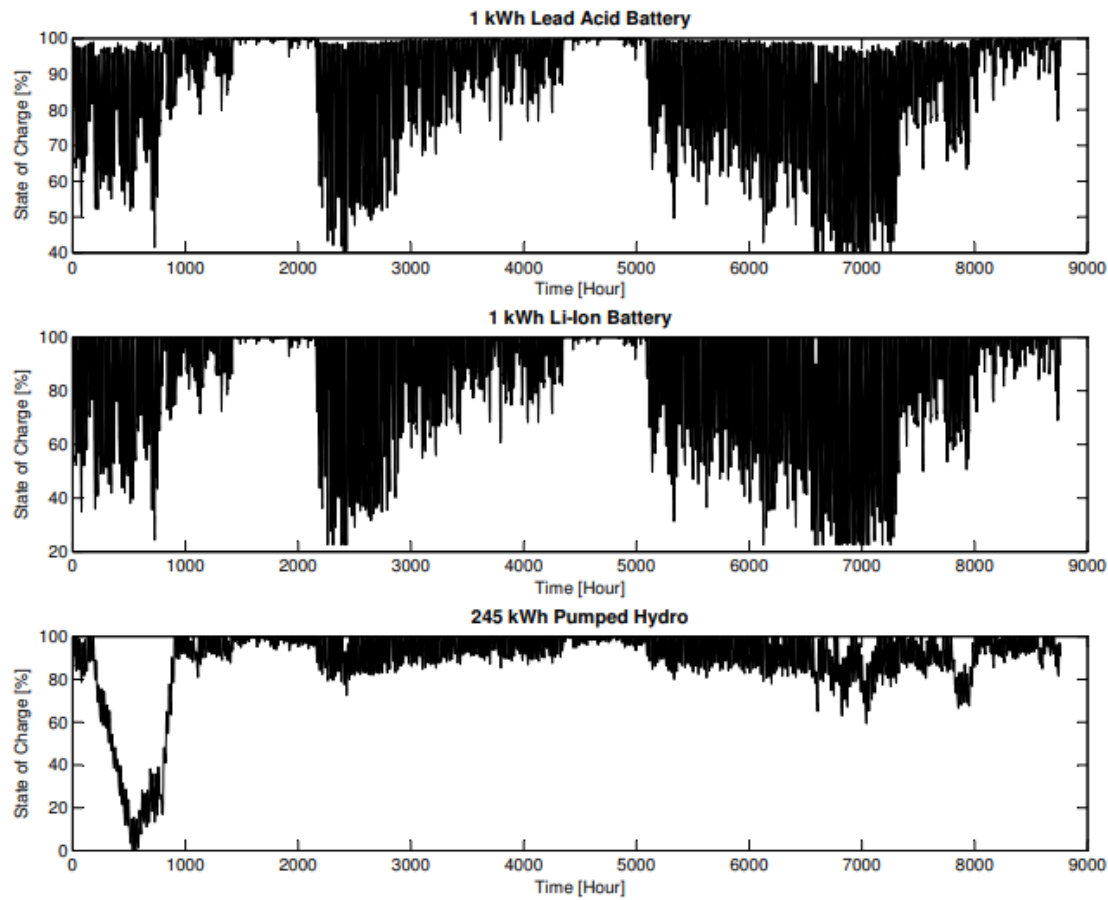

Figure 10

State of charge of the energy storage systems

\section{Conclusions}

This paper has presented a study of different energy storage technologies applied to a hybrid system composed of PV generator and HKT turbine. The results showed that all the systems analyzed satisfied over $99.8 \%$ of the energy required by the demand.

The system based of li-ion battery had the second lowest LCOE $(0.178 \$ / \mathrm{kWh})$, and the TNPC was $\$ 96,804$. The advantage of this configuration is a battery life with 15 years, whereas the disadvantage was the low autonomy ( $9 \mathrm{hr})$ of the stored energy.

The system based on lead acid battery had the third highest cost in LCOE (0.196 $\$ / \mathrm{kWh}$ ). The NPC was $\$ 106,854$, the autonomy of the system was $11.4 \mathrm{hr}$, but the expected life of the storage was reduced to $8.9 \mathrm{yr}$.

The system with hydrogen-based energy storage presented the highest TNPC $(\$ 189,639)$. However, it is expected that its implementation costs will be significantly reduced in the coming years and it is a totally ecological technology. 
The system based on pumped hydro obtained the best results in the unmet electric load $(10.4 \mathrm{kWh} / \mathrm{yr})$, TNPC $(\$ 86,995)$ and LCOE $(0.159 \$ / \mathrm{kWh})$. However, it presented the lowest expected life of the storage $(7 \mathrm{yr})$.

\section{References}

[1] World energy, "Latin America \&amp; The Caribbean." [Online]. Available: https://www.worldenergy.org/data/resources/region/latinamerica-the-caribbean/. [Accessed: 02-Feb-2018]

[2] "Renewable Capacity Statistics 2017," /publications/2017/Mar/RenewableCapacity-Statistics-2017, 2017

[3] J. Lata-Garcia, C. Reyes-Lopez, F. Jurado, L. M. Fernandez-Ramirez, and H. Sanchez, "Sizing optimization of a small hydro/photovoltaic hybrid system for electricity generation in Santay Island, Ecuador by two methods," in 2017 CHILEAN Conference on Electrical, Electronics Engineering, Information and Communication Technologies (CHILECON), 2017, pp. 1-6

[4] S. Ahmadi and S. Abdi, "Application of the Hybrid Big Bang-Big Crunch algorithm for optimal sizing of a stand-alone hybrid PV/wind/battery system," Sol. Energy, Vol. 134, 2016, pp. 366-374

[5] A. Cano, F. Jurado, H. Sánchez, L. M. Fernández, and M. Castañeda, "Optimal sizing of stand-alone hybrid systems based on PV/WT/FC by using several methodologies," J. Energy Inst., Vol. 87, No. 4, 2014, pp. 330-340

[6] S. O. Amrouche, D. Rekioua, and T. Rekioua, "Overview of energy storage in renewable energy systems," in $20153^{\text {rd }}$ International Renewable and Sustainable Energy Conference (IRSEC), 2015, pp. 1-6

[7] A. K. Rohit and S. Rangnekar, "An overview of energy storage and its importance in Indian renewable energy sector: Part II - energy storage applications, benefits and market potential," J. Energy Storage, Vol. 13, Oct. 2017, pp. 447-456

[8] A. Evans, V. Strezov, and T. J. Evans, "Assessment of utility energy storage options for increased renewable energy penetration," Renew. Sustain. Energy Rev., Vol. 16, No. 6, Aug. 2012, pp. 4141-4147

[9] J. Lata-García, F. Jurado, L. M. Fernández-Ramírez, and H. Sánchez-Sainz, "Optimal hydrokinetic turbine location and techno-economic analysis of a hybrid system based on photovoltaic/hydrokinetic/hydrogen/battery," Energy, Vol. 159, Sep. 2018, pp. 611-620

[10] J. C. Spall, "Multivariate stochastic approximation using a simultaneous perturbation gradient approximation," IEEE Trans. Automat. Contr., Vol. 37, No. 3, Mar. 1992, pp. 332-341

[11] A. Ürmös, Z. Farkas, M. Farkas, T. Sándor, L. T. Kóczy, and Á. Nemcsics, 
"Application of Self-Organizing Maps for Technological Support of Droplet Epitaxy"

[12] A. Impr. Bourg-offset), D. Kumar, and S. K. Jarial, A Hybrid Clustering Method Based on Improved Artificial Bee Colony and Fuzzy C-Means Algorithm, Vol. 15, No. 2. Fontaine Picard, 1997

[13] B. Das and A. Kumar, "A NLP approach to optimally size an energy storage system for proper utilization of renewable energy sources," Procedia Comput. Sci., Vol. 125, Jan. 2018, pp. 483-491

[14] A. S. Jacob, R. Banerjee, and P. C. Ghosh, "Sizing of hybrid energy storage system for a PV based microgrid through design space approach," Appl. Energy, Vol. 212, Feb. 2018, pp. 640-653

[15] Y. Yang, S. Bremner, C. Menictas, and M. Kay, "Battery energy storage system size determination in renewable energy systems: A review," Renew. Sustain. Energy Rev., Vol. 91, Aug. 2018, pp. 109-125

[16] S. Bahramara, M. P. Moghaddam, and M. R. Haghifam, "Optimal planning of hybrid renewable energy systems using HOMER: A review," Renew. Sustain. Energy Rev., Vol. 62, 2016, pp. 609-620

[17] T. M. I. Mahlia, T. J. Saktisahdan, A. Jannifar, M. H. Hasan, and H. S. C. Matseelar, "A review of available methods and development on energy storage; technology update," Renew. Sustain. Energy Rev., Vol. 33, May 2014, pp. 532-545

[18] Amin, R. T. Bambang, A. S. Rohman, C. J. Dronkers, R. Ortega, and A. Sasongko, "Energy Management of Fuel Cell/Battery/Supercapacitor Hybrid Power Sources Using Model Predictive Control," IEEE Trans. Ind. Informatics, Vol. 10, No. 4, Nov. 2014, pp. 1992-2002

[19] Policy department Economic and Scientific, "Outlook of energy storage technologies"

[20] University Basque country, "Energy Storage Technologies for Electric Applications." [Online]. Available: http://www.sc.ehu.es/sbweb/energiasrenovables/temas/almacenamiento_1/almacenamiento_1.html [Accessed: 10-Feb-2018]

[21] A. Raj K, S. Bag, A. Roy, U. Pal, and S. Mitra, "Battery Technologies for Energy Storage," in Encyclopedia of Sustainable Technologies, Elsevier, 2017, pp. 469-486

[22] C. Wang, M. H. Nehrir, and S. R. Shaw, "Dynamic Models and Model Validation for PEM Fuel Cells Using Electrical Circuits," IEEE Trans. Energy Convers., Vol. 20, No. 2, Jun. 2005, pp. 442-451

[23] S. Kapila, A. O. Oni, and A. Kumar, "The development of technoeconomic models for large-scale energy storage systems," Energy, Vol. 140, Dec. 2017, pp. 656-672 
[24] Smart Hydro Power, "Smart monofloat turbine.” Postdam, p. 1, 2015

[25] M. Mehrabankhomartash, M. Rayati, A. Sheikhi, and A. M. Ranjbar, "Practical battery size optimization of a PV system by considering individual customer damage function," Renew. Sustain. Energy Rev., Vol. 67, 2017, pp. 36-50

[26] "PEM fuel cell degradation effects on the performance of a stand-alone solar energy system," Int. J. Hydrogen Energy, Vol. 42, No. 18, May 2017, pp. $13217-13225$

[27] C. Ghenai and M. Bettayeb, "Modelling and performance analysis of a stand-alone hybrid solar PV/Fuel Cell/Diesel Generator power system for university building," Energy, Vol. 171, Mar. 2019, pp. 180-189

[28] P. Millet, S. Grigoriev, P. M. Diéguez, P. Millet, and S. Grigoriev, "Water Electrolysis Technologies," in Renewable Hydrogen Technologies, Elsevier, 2013, pp. 19-41

[29] "HOMER - Hybrid Renewable and Distributed Generation System Design Software" [Online] Available: http://www.homerenergy.com/ [Accessed: 18-Apr-2017]

[30] "Plan Maestro de Electrificación 2013- 2022, Volume 2, Pag 42, Residential load curve, Guayaquil electric," 2017

[31] "Instituto Oceanográfico de la Armada - Tabla de mareas puertos del Ecuador" [Online] Available:

http://www.inocar.mil.ec/web/index.php/productos/tabla-mareas [Accessed: 29-Apr-2017]

[32] HOMER, "Maximum Annual Capacity Shortage" [Online] Available: https://www.homerenergy.com/support/docs/3.11/maximum_annual_capaci ty_shortage.html [Accessed: 28-Dec-2017] 